\title{
The change of stroke volume variation during thoracotomy or one lung ventilation
}

Received August 28, 2018

Revised 1st, October 4, 2018

2nd, October 20, 2018

Accepted October 21, 2018

\section{Corresponding author}

Deokkyu Kim, M.D., Ph.D. Department of Anesthesiology and Pain Medicine, Chonbuk National University Medical School and Hospital, 20 Geonji-ro, Deokjin-gu, Jeonju 54907, Korea

Tel: 82-63-250-1241

Fax: 82-63-250-1240

E-mail: aneduke@jbnu.ac.kr ORCID

https://orcid.org/0000-0001-7613-3529

\section{Hyungsun Lim, Dong-Chan Kim, Myung-Jong Kim, Seonwoo Yoo, Min-Jong Ki, Sehrin Kang, and Deokkyu Kim}

Department of Anesthesiology and Pain Medicine, Chonbuk National University Medical School and Hospital, Jeonju, Korea

Background: Stroke volume variation (SVV) is based on cyclic changes of intrathoracic pressure during respiratory cycle. Thoracotomy and one-lung ventilation (OLV) can lead to changes in airway and intrathoracic pressure. The aim of this study was to determine whether thoracotomy and converting from two lung ventilation to OLV could affect SVV values.

Methods: Thirty patients who were scheduled for pulmonary lobectomy or pneumonectomy requiring OLV were enrolled. Induction and maintenance of anesthesia were performed with propofol and remifentanil via total intravenous anesthesia. Hemodynamic variables including mean arterial pressure (MAP), heart rate (HR), cardiac index (CI), and SVV were measured at intervals of $1 \mathrm{~min}$ for $10 \mathrm{~min}$ after thoracotomy and OLV, respectively.

Results: MAP and HR increased from baseline at intervals between 3 and 10 min and between 4 and 10 min after thoracotomy, respectively $(P<0.001)$. Cl increased between 4 and $10 \mathrm{~min}(\mathrm{P}<0.001)$. SV did not change for $10 \mathrm{~min}$ after thoracotomy. After OLV, MAP decreased between 4 and $10 \mathrm{~min}(P=0.112)$. SVV was the highest at $1 \mathrm{~min}$ after OLV. It returned to the baseline value at $7 \mathrm{~min}(\mathrm{P}<0.001)$. $\mathrm{Cl}$ decreased between 8 and 10 min after OLV $(P<0.001)$.

Conclusions: SVV can increase after OLV temporarily. Transient increase of SVV may be considered when fluid responsiveness is predicted by SVV during early period after OLV.

Keywords: One lung ventilation; Stroke volume; Thoracotomy.

\section{INTRODUCTION}

The Vigileo-FloTrac ${ }^{\circledR}$ system (Edwards Lifesciences, USA), founded on the analysis of arterial pressure wave, is used for automatic and continuous monitoring of cardiac output and stroke volume variation (SVV). The reliability of this system to measure cardiac output has been established in numerous settings with various results [1-7]. In addition, SVV measured by this device has been found to be capable of predicting fluid responsiveness in patients with mechanical ventilation [8-12].
In thoracic surgery, lung resection and/or one lung ventilation (OLV) may cause postoperative acute lung injury [13-15]. In such cases, fluid management is important. Intraoperative fluid overloading is a significant predictor of postoperative lung injury $[16,17]$. Fluid restriction is usually recommended for lung surgery [17-19]. Thoracotomy (open thorax) and OLV can lead to changes in airway and intrathoracic pressure. Because SVV is based on cyclic changes of intrathoracic pressure during the respiratory cycle, the usefulness of SVV to predict fluid responsiveness is conflicting under the open

This is an Open Access article distributed under the terms of the Creative Commons Attribution Non-Commercial License (http://creativecommons.org/licenses/by-nc/4.0) which permits unrestricted non-commercial use, distribution, and reproduction in any medium, provided the original work is properly cited.

Copyright (c) the Korean Society of Anesthesiologists, 2019 
chest conditions [20-24]. However, previous studies have reported that SVV can predict fluid responsiveness in patients during OLV under thoracoscopy $[25,26]$.

Most studies for open chest and/or OLV have focused on the usefulness of SVV for predicting fluid responsiveness. However, no study has reported whether thoracotomy or OLV affects changes of SVV when the fluid volume is sufficient. Thus, the aim of this study was to determine whether thoracotomy and converting from two lung ventilation (TLV) to OLV might affect values of SVV and the hemodynamic change using Vigileo-FloTrac ${ }^{\circledR}$ system.

\section{MATERIALS AND METHODS}

This study was approved by the institutional review board of Chonbuk National University Hospital (no. 2011-01-007). All patients provided written informed consent before surgery. Thirty patients aged 20 to 65 years who were scheduled for pulmonary lobectomy or pneumonectomy requiring OLV were enrolled in this study. Exclusion criteria were: American Society of Anesthesiologists physical status $\geq$ III, cardiac arrhythmia, or severe obesity with a body mass index $\geq 35$.

Electrocardiography, pulse oximetry, and noninvasive blood pressure monitoring were applied upon arrival in the operating room. Induction and maintenance of anesthesia were performed with propofol (target concentration of 3-5 $\mu \mathrm{g} / \mathrm{ml})$ and remifentanil (3-5 $\mathrm{ng} / \mathrm{ml})$ via total intravenous anesthesia, and the depth of anesthesia was maintained at bispectral index (BIS) of 40-55 using a BIS monitor (BIS $\mathrm{VISTA}^{\mathrm{TM}}$, Aspect, USA). Endotracheal intubation with leftsided double-lumen tube (Mallinckrodt ${ }^{\mathrm{TM}}$, Covidien, USA) was facilitated by rocuronium $(1.0 \mathrm{mg} / \mathrm{kg})$, and the location of double-lumen tube was confirmed using a fiberoptic bronchoscope. An arterial catheter was inserted in the left or right radial artery. Cardiac output and SVV were measured using a Vigileo-FloTrac ${ }^{\circledR}$ system (Vigileo $^{\mathrm{TM}}$, Edwards Lifesciences).

Patients' lungs were mechanically ventilated with a tidal volume of $8 \mathrm{ml} / \mathrm{kg}$ (ideal body weight) during both TLV and OLV. The inspired oxygen fraction was 0.5 during TLV and 1.0 during OLV. The inspiratory to expiratory time ratio was $1: 2$. The inspiratory pause time was $20 \%$ while the positive endexpiratory pressure (PEEP) was $3 \mathrm{cmH}_{2} \mathrm{O}$ (intrinsic PEEP of circuit). The respiratory rate was adjusted to maintain endtidal carbon dioxide tension at 30 to 35 during TLV and 35 to
$40 \mathrm{mmHg}$ during OLV.

After induction of anesthesia, patient's position was changed to lateral decubitus. To minimize the effect of anesthesia induction on SVV, all patients were administered 3-5 $\mathrm{ml} / \mathrm{kg}$ of crystalloid fluid intravenously after the induction of anesthesia, and kept $2 \mathrm{ml} / \mathrm{kg} / \mathrm{h}$ until skin incision. Additional fluid was administered when bleeding was observed or when it was deemed necessary by attending anesthesiologists. This was proceeded only when a patient met the following criteria: cardiac index $(\mathrm{CI}) \geq 2.5 \mathrm{~L} / \mathrm{min} / \mathrm{m}^{2}$ and $\mathrm{SVV} \leq 10 \%$. Hemodynamic variables including heart rate (HR), mean arterial pressure (MAP), CI, and SVV were measured at intervals of $1 \mathrm{~min}$ for $10 \mathrm{~min}$ after thoracotomy and OLV, respectively. For all subjects, thoracotomy and OLV were carried out. In order to collect hemodynamic variables of thoracotomy itself, surgical procedure was held when the muscle of chest wall was dissected with surgeon's cooperation. Baseline data were collected after waiting for stabilized vital sign just before thoracotomy. Also, post-thoracotomy data were collected for 10 min after the thoracotomy with stabilized vital sign in the absence of surgical stimuli.

Anesthetic depth was adjusted for stabilizing the vital sign within $20 \%$ of preoperative vital signs. When the vital sign was stable for more than $5 \mathrm{~min}$, baseline values were collected and hemodynamic parameters were then recorded for 10 min after thoracotomy without surgical stimulus. Hemodynamic variables from TLV to OLV were also collected in the absence of surgical manipulation. Tidal volume during OLV was kept at $8 \mathrm{ml} / \mathrm{kg}$ (based on ideal body weight) as TLV, and plateau airway pressure was collected before and after thoracotomy and OLV.

All statistical analyses were performed using SigmaPlot 12.0 (Systat Software Inc., USA). All data are expressed as mean \pm SD and median $(1 Q, 3 Q)$ except number of patients. Normality test was performed for all variables with the Shapiro-Wilk test. Some hemodynamic variables violated the normality. These variables were evaluated with repeated measures analysis of variance (ANOVA) on ranks and Dunnett's method was applied as post-hoc test. Data of airway pressure were analyzed with a paired $t$-test. Statistical significance was considered at $\mathrm{P}<0.05$. 


\section{RESULTS}

Seventeen male and 13 female patients were enrolled in this study. Their mean age, height, and weight were $56.3 \pm$ 13.3 years, $160.7 \pm 10.5 \mathrm{~cm}$, and $59.5 \pm 10.9 \mathrm{~kg}$, respectively. Since the baseline value of SVV was more than $10 \%$ in 5 patients for thoracotomy and 6 patients for OLV, hemodynamic data were analyzed for 25 patients after thoracotomy and 24 patients after OLV.

After thoracotomy, MAP and HR increased at 3-10 and 4-10 min, respectively $(\mathrm{P}<0.001)$. CI increased at $4-10 \min (\mathrm{P}<$ 0.001). SVV was not changed for $10 \mathrm{~min}$ after thoracotomy (P $=0.084$, Fig. 1). Plateau airway pressure decreased from 14.5 \pm 2.2 to $10.1 \pm 3.5 \mathrm{cmH}_{2} \mathrm{O}$ after thoracotomy $(\mathrm{P}<0.001)$.
After starting OLV, MAP decreased at 4-10 min $(\mathrm{P}<0.001)$ while HR did not change for $10 \mathrm{~min}$. SVV increased to the highest at $1 \mathrm{~min}$ after OLV and returned to the baseline value at $7 \mathrm{~min}(\mathrm{P}=0.112)$. SVV temporarily increased above $15 \%$ for 4 patients. Cardiac index decreased at 8-10 $\min (\mathrm{P}<0.001$, Fig. 2). Plateau airway pressure increased from $11.4 \pm 2.7$ to $17.9 \pm 4.4 \mathrm{cmH}_{2} \mathrm{O}$ after $\mathrm{OLV}(\mathrm{P}<0.001)$.

\section{DISCUSSION}

The main finding of this study was that cardiac output was mildly increased after thoracotomy whereas it was gradually decreased during OLV. SVV obtained from a Vigileo-FloTrac ${ }^{\circledR}$ system temporarily increased after OLV and not changed in
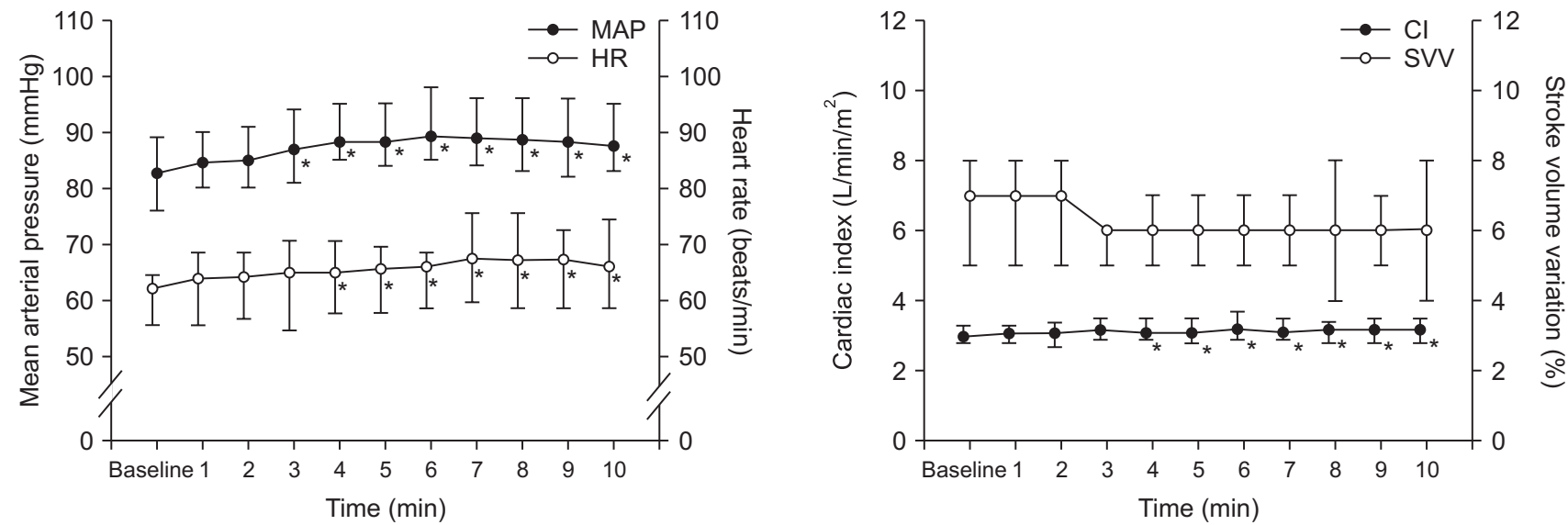

Fig. 1. Change of hemodynamics after thoracotomy. Mean arterial pressure (MAP) and heart rate (HR) increased at 3-10 and 4-10 min, respectively $(P<0.001)$. Cardiac index $(\mathrm{Cl})$ increased at $4-10 \mathrm{~min}(\mathrm{P}<0.001)$. Stroke volume variation $(\mathrm{SW})$ was not changed for $10 \mathrm{~min}(\mathrm{P}=0.084)$. Values are presented as medians (1Q, 3Q). $* P<0.05$ vs. baseline value.
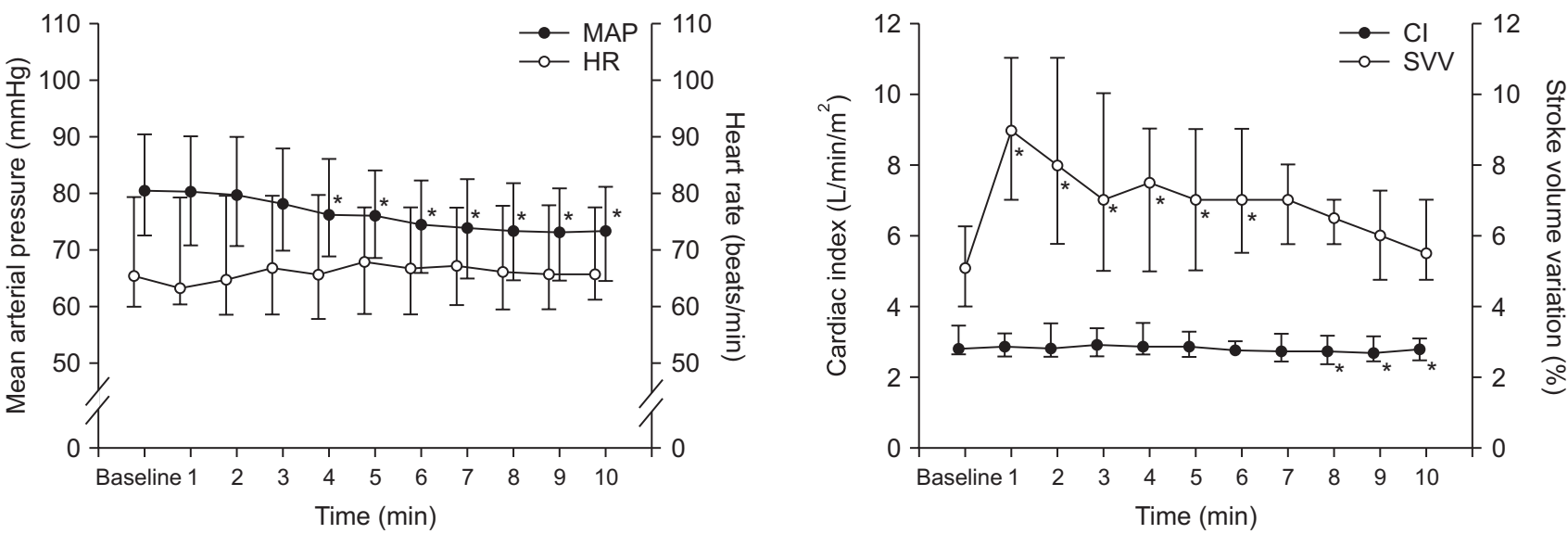

Fig. 2. Change of hemodynamics after one lung ventilation. Mean arterial pressure $(M A P)$ decreased at $4-10$ min $(P<0.001)$ while heart rate $(H R)$ did not changed $(P=0.112)$. Stroke volume variation $(\mathrm{SW})$ increased to the highest at $1 \mathrm{~min}$ and returned to the baseline value at $7 \mathrm{~min}$. Cardiac index $(\mathrm{Cl})$ decreased at 8-10 $\min (\mathrm{P}<0.001)$. Values are medians $(1 \mathrm{Q}, 3 \mathrm{Q})$. $* \mathrm{P}<0.05$ vs. baseline value. 
thoracotomy. This temporary increase of SVV after change from TLV to OLV should be considered when fluid responsiveness is predicted by SVV using a Vigileo-FloTrac ${ }^{\circledR}$ system during the early period after starting OLV.

SVV is based on the interaction between heart and lung by the cyclic changes of intrathoracic pressure. At the inspiratory phase, increased alveolar pressure leads to purge of pulmonary venous blood into the left heart that can increase left ventricular stroke volume [25]. However, increased intrathoracic pressure can decrease venous return to the right heart and increase afterload of the right ventricle. Approximately three heartbeats later, this decrease in stoke volume of the right ventricle can result in a decrease in the left ventricular stroke volume at the expiratory phase $[8,26]$. Cannesson et al. [8] have reported that a threshold SVV value of $10 \%$ allows discrimination of responders to volume loading with a sensitivity of $82 \%$ and a specificity of $88 \%$.

In this study, before thoracotomy and OLV, fluid was administered sufficiently for volume deficiency such as vasodilatation, bleeding, and third space loss. The protocol proceeded only in patient who had over five minutes of hemodynamic stability, cardiac index $\geq 2.5 \mathrm{~L} / \mathrm{min} / \mathrm{m}^{2}$, and SVV $\leq 10 \%$ under no surgical manipulation. To avoid hypovolemia as much as possible, the criterion of SVV was set at $10 \%$. After thoracotomy, MAP and CI increased while SVV did not change in our results. Theoretically, a relatively small change in intrathoracic pressure by open thorax during inspiration does not interrupt systemic venous return (preload) to right heart while the left ventricular stroke volume during expiration is preserved. Therefore, an increase in minimum stroke volume can result in a decrease in SVV value. However, SVV was not changed in our study because the baseline value might be less than $10 \%$. According to De Blasi et al. [27], pulse pressure variation (PPV) was decreased after sternotomy for patients whose PPV was more than $8 \%$ while PPV was unchanged for patients whose PPV was less than $8 \%$. Decreases in intrathoracic pressure can increase preload of the right heart and decrease afterload, thus increasing MAP and CI.

After starting OLV under thoracotomy, the value of SVV measured with a Vigileo-FloTrac ${ }^{\circledR}$ system was temporarily increased. It then returned to the baseline value. During OLV, ventilated and non-ventilated lungs might have changed differently. When tidal volume was kept and OLV was started, increased transpulmonary pressure purges pulmonary ve- nous blood into the left heart in ventilated lung. On the other hand, such effect of the purge of pulmonary venous blood does not exist in non-ventilated lung. As a blood flow toward the dependent lung in lateral position is increased by gravity, the effect of dependent lung might be greater than the other, thus increasing the maximum SV. When OLV was started, MAP and CI decreased as time passed during the operation. According to Kozian et al. [15], cardiac output decreases in pig under thoracotomy and OLV due to non-ventilated lung collapse, hypoxic pulmonary vasoconstriction, and increased afterload of the right ventricle by increased airway pressure in ventilated lung. It is challenging to explain the cause of decrease of SVV to the baseline.

In most recent cases, tidal volume is set at $6 \mathrm{ml} / \mathrm{kg}$ with 5 $\mathrm{cm} \mathrm{H}_{2} \mathrm{O}$ of PEEP during OLV. However, tidal volume was set at $8 \mathrm{ml} / \mathrm{kg}$ in this study. Suehiro and Okuni [28] have proposed that SVV could predict fluid responsiveness in OLV only when tidal volume is at least $8 \mathrm{ml} / \mathrm{kg}$. Therefore, we did not apply PEEP to remove the hemodynamic influence of PEEP.

The use of SVV or dynamic variables is increasing for fluid management of perioperative or intensive care unit patients with ventilation. A Vigileo-FloTrac ${ }^{\circledR}$ system via arterial pressure wave have advantages because cardiac output can be monitored automatically and continuously with VigileoFloTrac $^{\circledR}$, but not with echocardiogram or aortic Doppler. In addition, it is less invasive than pulmonary catheterization. With these advantages, this device may be utilized as a bedside point-of-care device. However, SVV is affected by tidal volume, respiratory rate, and intrathoracic pressure $[29,30]$ and the absolute value of cardiac output is less accurate when systemic vascular resistance (SVR) is decreased [11] or under hyperdynamic condition [2]. Although SVR was not measured in this study, changes in SVR due to anesthetic depth and effects of anesthetics may alter the effective circulating volume. Thus, clinicians should be cautious when interpreting cardiac output and SVV obtained from the arterial pulse wave. In the present study, although there was no decrease in actual intravascular volume, there was a temporary increase in SVV during OLV.

The present study has some limitations. First, we did not measure the cardiac output from a pulmonary artery catheter or echocardiogram. However, a Vigileo-FloTrac ${ }^{\circledR}$ system has been a clinically acceptable device to measure cardiac 
output [1-5]. In addition, cardiac index and SVV were within normal ranges during the study. Second, because the present study was conducted during surgery, changes of hemodynamic variables might not be due to thoracotomy and OLV absolutely. Although we have tried to exclude surgical stimuli during this study, it may be possible to make hemodynamic depression by anesthesia. However, this is a similar problem in most clinical studies have. Third, because similar previous studies were unavailable, the sample size was randomly calculated to be 30 patients. Therefore, the results of this study may be characteristics of a preliminary study. Further study with a strict sample size calculation is needed. Fourth, hypoxic pulmonary vasoconstriction (HPV) in OLV is an important mechanism that controls the pulmonary shunt. Parameters that might affect HPV were not included in this study. However, desaturation under $96 \%$ of pulse oximetry did not occur in this study. Lastly, we used less conservative post hoc test for statistical analysis because this was the first study to figure out the effect of thoracotomy and OLV on SVV changes in patients with adequate fluid volume based on SVV values monitored with Vigileo-FloTrac ${ }^{\circledR}$. Since our statistical analysis cannot control for the occurrence of type I errors clearly, more conservative comparative methods are needed for subsequent studies.

Most studies for open chest and/or OLV have focused on the usefulness of SVV for predicting fluid responsiveness. Unlike previous studies proving that SVV can predict fluid responsiveness, the present study is focused on the effect of thoracotomy or OLV itself on changes of SVV when fluid volume is sufficient.

In conclusion, SVV measured by a Vigileo-FloTrac ${ }^{\circledast}$ system is increased after OLV temporarily. Such a transient increase of SVV may be considered when fluid responsiveness is predicted by SVV during early period after OLV. Therefore, fluid status with only SVV should not be predicted.

\section{CONFLICTS OF INTEREST}

No potential conflict of interest relevant to this article was reported.

\section{ORCID}

Hyungsun Lim: https://orcid.org/0000-0002-6379-9302
Dong-Chan Kim: https://orcid.org/0000-0002-6881-126X

Myung-Jong Kim: https://orcid.org/0000-0002-0031-2253

Seonwoo Yoo: https://orcid.org/0000-0002-1742-7487

Min-Jong Ki: https://orcid.org/0000-0001-9959-7908

Sehrin Kang: https://orcid.org/0000-0001-8211-3831

\section{REFERENCES}

1. Lorsomradee S, Lorsomradee S, Cromheecke S, De Hert SG. Uncalibrated arterial pulse contour analysis versus continuous thermodilution technique: effects of alterations in arterial waveform. J Cardiothorac Vasc Anesth 2007; 21: 636-43.

2. Della Rocca G, Costa MG, Chiarandini P, Bertossi G, Lugano M, Pompei L, et al. Arterial pulse cardiac output agreement with thermodilution in patients in hyperdynamic conditions. J Cardiothorac Vasc Anesth 2008; 22: 681-7.

3. Breukers RM, Sepehrkhouy S, Spiegelenberg SR, Groeneveld AB. Cardiac output measured by a new arterial pressure waveform analysis method without calibration compared with thermodilution after cardiac surgery. J Cardiothorac Vasc Anesth 2007; 21: 632-5.

4. Manecke GR Jr, Auger WR. Cardiac output determination from the arterial pressure wave: clinical testing of a novel algorithm that does not require calibration. J Cardiothorac Vasc Anesth 2007; 21:3-7.

5. Marik PE. Techniques for assessment of intravascular volume in critically ill patients. J Intensive Care Med 2009; 24: 329-37.

6. Jang EA, Lee SE, Choi JI, Cho SY. Changes in the hemodynamic parameters between the prone and supine positions measured by an arterial pulse contour cardiac output monitoring system. Anesth Pain Med 2015; 10: 291-4.

7. Kim HJ, Jung YS, Kim JH, Bahk JH, Gil NS, Lim YJ, et al. Predictability of passive leg raising test on anesthesia-induced hypotension in patients undergoing cardiac surgery. Anesth Pain Med 2013; 8: 104-11.

8. Cannesson M, Musard H, Desebbe O, Boucau C, Simon R, Hénaine $\mathrm{R}$, et al. The ability of stroke volume variations obtained with Vigileo/FloTrac system to monitor fluid responsiveness in mechanically ventilated patients. Anesth Analg 2009; 108: 513-7.

9. Biais M, Nouette-Gaulain K, Roullet S, Quinart A, Revel P, Sztark F. A comparison of stroke volume variation measured by Vigileo/ FloTrac system and aortic Doppler echocardiography. Anesth Analg 2009; 109: 466-9.

10. Biais M, Nouette-Gaulain K, Quinart A, Roullet S, Revel P, Sztark F. Uncalibrated stroke volume variations are able to predict the hemodynamic effects of positive end-expiratory pressure in patients with acute lung injury or acute respiratory distress syn- 
drome after liver transplantation. Anesthesiology 2009; 111: 85562.

11. Biais M, Nouette-Gaulain K, Cottenceau V, Revel P, Sztark F. Uncalibrated pulse contour-derived stroke volume variation predicts fluid responsiveness in mechanically ventilated patients undergoing liver transplantation. Br J Anaesth 2008; 101: 761-8.

12. Benes J, Chytra I, Altmann P, Hluchy M, Kasal E, Svitak R, et al. Intraoperative fluid optimization using stroke volume variation in high risk surgical patients: results of prospective randomized study. Crit Care 2010; 14: R118.

13. Eichenbaum KD, Neustein SM. Acute lung injury after thoracic surgery. J Cardiothorac Vasc Anesth 2010; 24: 681-90.

14. Cheng YJ, Chan KC, Chien CT, Sun WZ, Lin CJ. Oxidative stress during 1-lung ventilation. J Thorac Cardiovasc Surg 2006; 132: 513-8.

15. Kozian A, Schilling T, Fredén F, Maripuu E, Röcken C, Strang C, et al. One-lung ventilation induces hyperperfusion and alveolar damage in the ventilated lung: an experimental study. Br J Anaesth 2008; 100: 549-59.

16. Alam N, Park BJ, Wilton A, Seshan VE, Bains MS, Downey RJ, et al. Incidence and risk factors for lung injury after lung cancer resection. Ann Thorac Surg 2007; 84: 1085-91.

17. Licker M, de Perrot M, Spiliopoulos A, Robert J, Diaper J, Chevalley $\mathrm{C}$, et al. Risk factors for acute lung injury after thoracic surgery for lung cancer. Anesth Analg 2003; 97: 1558-65.

18. Brister NW, Barnette RE, Kim V, Keresztury M. Anesthetic considerations in candidates for lung volume reduction surgery. Proc Am Thorac Soc 2008; 5: 432-7.

19. Sentürk M. New concepts of the management of one-lung ventilation. Curr Opin Anaesthesiol 2006; 19: 1-4.

20. Reuter DA, Goepfert MS, Goresch T, Schmoeckel M, Kilger E, Goetz AE. Assessing fluid responsiveness during open chest conditions. Br J Anaesth 2005; 94: 318-23.

21. Reuter DA, Goresch T, Goepfert MS, Wildhirt SM, Kilger E, Goetz
AE. Effects of mid-line thoracotomy on the interaction between mechanical ventilation and cardiac filling during cardiac surgery. Br J Anaesth 2004; 92: 808-13.

22. de Waal EE, Rex S, Kruitwagen CL, Kalkman CJ, Buhre WF. Dynamic preload indicators fail to predict fluid responsiveness in open-chest conditions. Crit Care Med 2009; 37: 510-5.

23. Wyffels PA, Sergeant P, Wouters PF. The value of pulse pressure and stroke volume variation as predictors of fluid responsiveness during open chest surgery. Anaesthesia 2010; 65: 704-9.

24. Sander M, Spies CD, Berger K, Grubitzsch H, Foer A, Krämer M, et al. Prediction of volume response under open-chest conditions during coronary artery bypass surgery. Crit Care 2007; 11: R121.

25. Vieillard-Baron A, Chergui K, Augarde R, Prin S, Page B, Beauchet $\mathrm{A}$, et al. Cyclic changes in arterial pulse during respiratory support revisited by Doppler echocardiography. Am J Respir Crit Care Med 2003; 168: 671-6.

26. Michard F. Changes in arterial pressure during mechanical ventilation. Anesthesiology 2005; 103: 419-28.

27. De Blasi RA, Palmisani S, Cigognetti L, Iasenzaniro M, Arcioni $\mathrm{R}$, Mercieri M, et al. Effects of sternotomy on heart-lung interaction in patients undergoing cardiac surgery receiving pressurecontrolled mechanical ventilation. Acta Anaesthesiol Scand 2007; 51: 441-6.

28. Suehiro K, Okutani R. Influence of tidal volume for stroke volume variation to predict fluid responsiveness in patients undergoing one-lung ventilation. J Anesth 2011; 25: 777-80.

29. Mesquida J, Kim HK, Pinsky MR. Effect of tidal volume, intrathoracic pressure, and cardiac contractility on variations in pulse pressure, stroke volume, and intrathoracic blood volume. Intensive Care Med 2011; 37: 1672-9.

30. De Backer D, Taccone FS, Holsten R, Ibrahimi F, Vincent JL. Influence of respiratory rate on stroke volume variation in mechanically ventilated patients. Anesthesiology 2009; 110: 1092-7. 